\title{
TALIAN: LÍNGUA NEGADA E (RE)CONHECIDA PELOS DESCENDENTES VÊNETOS DE CURITIBA E REGIÃO METROPOLITANA
}

\author{
Talian: a Denied Language, (Re)Cognized by Veneto's Descendants of \\ Curitiba and Metropolitan Region
}

Karine Marielly Rocha da CUNHA Universidade Federal do Paraná karinemrc@hotmail.com https://orcid.org/0000-0002-5184-0558

\author{
Diego GABARDO \\ Centro de Estudos Vênetos no Paraná - CEVEP \\ diegogabardo@gmail.com \\ https://orcid.org/0000-0003-1824-812X
}

RESUMO: Segundo o Instituto do Patrimônio Histórico Artístico Nacional - IPHAN, o Talian é uma das autodenominações para a língua de imigração falada no Brasil em algumas regiões de ocupação italiana, desde 1875. O Centro de Estudos Vênetos no Paraná - CEVEP tem essa língua como principal objeto de estudo e atribui à mesma o conceito de Ortale (2016) sobre língua de herança. Neste trabalho pretendemos ilustrar o resultado de algumas entrevistas realizadas com descendentes de imigrantes de segunda e terceira gerações, em sua maioria de origem vêneta e moradores de Curitiba e Região Metropolitana. O nosso escopo é analisar e entender a percepção de pertencimento desses imigrantes à cultura italiana e de como o Talian tem contribuído - ou não - para esse processo. A motivação para desenvolver tal análise nasce do fato de que, durante a Campanha de Nacionalização de Vargas era vetado exprimir-se em outra língua diferente do português. Isso fez com que muitos descendentes negassem a sua língua de herança, seja por medo ou por vergonha, fato que se reflete nas gerações seguintes. Apresentamos excertos das entrevistas que retratam tal sentimento de forma a reconstruir o processo de reconhecimento ou negação da identidade italiana pela memória discursiva como aborda Payer (2006). PALAVRAS-CHAVE: Talian; língua de herança; repressão linguística; CEVEP.

ABSTRACT: According to the National Artistic Heritage Institute IPHAN, Talian is one of the self-denominations for the language of immigration spoken in Brazil, in some regions of Italian occupation, 
since 1875. The Veneto Studies Center in Paraná - CEVEP has this language as its main object of study and attributes to it Ortale's (2016) same concept of heritage language. In this paper, we intend to illustrate the result of some interviews with descendants of second and third generation immigrants, mostly from Veneto, and residents of Curitiba and the Metropolitan Region. Our aim is to analyze and understand the perception of belonging of these immigrants to Italian culture and how Talian contributed - or not - to this process. The motivation in developing such an analysis arises from the fact that during Vargas Nationalization Campaign it was strictly vetoed expressing and communicating in a language other than Portuguese. This caused so many descendants to deny their heritage language, for either fear or shame, and this reflected on generations to come. We want to show excerpts of interviews that portray such feeling in order to reconstruct the process of recognition or denial of Italian identity through discursive memory, as approached by Payer (2006). KEYWORDS: Talian; heritage language; language repression; CEVEP.

RESUMO: Secondo el Instituto del Patrimònio Stòrico Artìstico Nassionae - IPHAN, el Talian el ze una dele autodenominassion dea éngoa de imigrassion che a ze palà sol Brasie in tante region de ocupassion italiana, fin dal 1875. El Sentro de Studii Véneti ntel Paranà - CEVEP a studia e a capisse come éngoa de eredità, come discore Ortale (2016). In questo laoro, portemo el resultado de alcune interviste fate con dissendenti de imigranti dela seconda e tersa generassion, quasi tuti de origine véneta, che i ze stà a Curitiba e Region Metropolitana. Voemo capir se iuri i se sente parte dea cultura italiana e se el Talian el ze drio giutar in questo prossesso o nò. A motivassion a ze che, soa Campagna de Nassionalizassion de Vargas, gera proibio palar nantra éngoa diferente del portoghese, el bresilian, come i dise. Questo ga fato con che tanti dissendenti a negasse, par paura o par vergogna, e questo ga sussedesto anca coe prossime generassion. Demo vedre tocatei de alcune interviste che porta a noantri questo sentimento par che cussita se possa refar el prossesso de ricognossimento o negassion dea identità italiana par medo dea memòria discorsiva, como discore Payer (2006). PAROECIAVE: Talian; éngoa de eredità; repression lengoìstica; CEVEP.

\section{INTRODUÇÃO}

Entre o final do século XIX e início do XX, o Brasil acolheu um grande número de imigrantes italianos que se estabeleceu nos estados de São Paulo, Minas Gerais, Espírito Santo, Paraná, Santa Catarina e Rio Grande do Sul. No Sudeste, a principal motivação 
era suprir as necessidades de mão de obra nos cafezais, enquanto no Sul, fazia-se necessária a ocupação dos vazios demográficos (TRENTO, 1988). A chegada de milhares de vênetos, lombardos, trentinos, friulanos, entre outros, trouxe consigo vários dialetos, tão variados quanto as regiões de origem desses imigrantes. Com o passar dos anos, a mescla entre esses falares, o português, a língua italiana ensinada nas escolas étnicas e católicas italianas (MASCHIO, 2012) e outras línguas locais, deram origem a uma nova língua: o Talian ${ }^{1}$. Presente, sobretudo, na região sul do país e no Espírito Santo, devido à grande colonização vêneta, essa koiné é conhecida também como dialeto vêneto, vêneto sulriograndense, vêneto brasileiro, dialeto italiano, entre outras denominações.

Reprimido durante o Estado Novo, principalmente, durante a Segunda Guerra Mundial, o Talian, ou vêneto-brasileiro, apesar de carregar consigo alguns estigmas, é ainda uma língua muito difundida em cidades brasileiras com presença de descendentes de imigrantes do norte da península itálica. Tamanha representatividade fez com que, em 2014, o IPHAN (Instituto do Patrimônio Histórico e Artístico Nacional) o reconhecesse como referência cultural brasileira. Grande parte desta conquista se deve ao Rio Grande do Sul, estado precursor na busca por esta chancela do governo brasileiro, que consegue manter ativas várias iniciativas promotoras da cultura dos ítalo-descendentes.

Ao analisar Curitiba e a sua Região Metropolitana, percebe-se também uma presença expressiva de descendentes de imigrantes, principalmente vênetos, que ainda preservam o Talian no seu repertório cultural. Neste contexto, em 2018, surge o CEVEP (Centro de Estudos Vênetos no Paraná) como um grupo de pesquisadores de diferentes áreas, membros das comunidades italianas de Campo Largo, Colombo, Curitiba e instituições culturais, com o objetivo de resguardar, descrever e analisar esta língua com base, sobretudo, nas teorias sociolinguísticas. O Grupo está registrado no Diretório dos Grupos de Pesquisas no Brasil do CNPq.

Este artigo tem por escopo mostrar o Talian como língua negada e (re)conhecida pelos descendentes de vênetos, partindo de entrevistas realizadas com eles, no decorrer de 2019, na capital paranaense e região metropolitana. Para tanto, está estruturado em duas partes a saber: na primeira, tratamos de pontos opostos, da repressão dessa língua à sua inserção no Inventário Nacional da Diversidade Linguística como referência cultural brasileira e as suas consequências do ponto de vista da identidade linguística; na segunda, apresentamos uma breve seleção de trechos e análises de entrevistas feitas com

\footnotetext{
${ }^{1}$ Dentro do CEVEP - Centro de Estudos Vênetos no Paraná instituímos a grafia do ‘talian' sempre com a inicial maiúscula, portanto, Talian.
} 
os detentores dessa língua que retratam sentimentos de vergonha, negação e aceitação em relação à mesma. Por fim, fecharemos com as nossas considerações finais sobre o tema abordado.

\title{
TALIAN: NEGAÇÃO E (RE)CONHECIMENTO
}

\section{Questões linguísticas no Governo Vargas}

Vargas governou o Brasil, de forma ininterrupta, de 1930 a 1945. Inicialmente, durante o Governo Provisório (de 1930 a 1934), apresentou um caráter mais populista (instituição do voto feminino, obrigatoriedade e gratuidade do ensino primário e criação do Ministério do Trabalho, Indústria e Comércio) conquistando as massas, o que aconteceu, de certa forma, também no início do terceiro governo quando as propagandas do governo lhe eram favoráveis. Durante o Governo Constitucional (1934 a 1937) e o Estado Novo (1937 a 1945) sua postura foi nitidamente autoritária e centralizadora. A censura esteve cada vez mais presente, sobretudo durante o último governo, confirmando-se com a criação do Departamento de Imprensa e Propaganda - DIP. Estava então instaurado o Regime Ditatorial da Era Vargas.

Durante o Estado Novo foi implantada a Campanha de Nacionalização que Balthazar (2016) define como:

\begin{abstract}
uma série de medidas tomadas durante o governo de Getúlio Vargas com objetivo de minimizar e diminuir as influências estrangeiras no Brasil para o fortalecimento e a integração da sua população. Essa campanha ocorreu durante o regime político do Estado Novo, caracterizado pela centralização do poder, nacionalismo, anticomunismo e autoritarismo. Durou de outubro de 1937 até outubro de 1945 e gerou muitas atitudes linguísticas negativas em relação à língua italiana/dialeto na região sul do estado. (BALTHAZAR, 2016, p. 198)
\end{abstract}

As atitudes linguísticas negativas em relação à língua italiana e os seus dialetos foram percebidas em outras localidades, além da região sul de Santa Catarina, objeto de estudo da autora citada. Onde houvesse a difusão e prática de uma língua diferente da portuguesa essa deveria ser reprimida e substituída. As repressões aconteceram com maior ou menor intensidade dependendo "da personalidade" dos governos interventores nomeados por Vargas para os Estados.

A Campanha de Nacionalização tornou-se mais ferrenha em 1942, quando o 
Brasil declarou apoio aos Estados Unidos e, consequentemente, tornou-se inimigo dos países do Eixo. Naquele momento, mais do que nunca, era importante ter e defender uma identidade nacional e repudiar qualquer manifestação que não remetesse à nação brasileira. Várias ações foram adotadas para defender e enaltecer o purismo linguístico.

Durante o Estado Novo, escolas étnicas foram fechadas ou transformadas em escolas públicas (RENK \& MASCHIO, 2020). Centralizando as crianças em um ambiente supostamente monolíngue, buscava-se garantir a alfabetização na língua nacional, o português, já que, conforme aponta Fáveri (2002, p. 81), “a escolarização passou a ser um problema de segurança nacional". As línguas mais "perseguidas", segundo Campos (2006), eram o alemão, o japonês e o italiano. Constatação não estranha, já que os países dessas línguas faziam parte do Eixo e o Brasil estava com os Aliados. Neste período de repressão, percebemos que:

No esforço de nacionalizar pela unificação da língua, denúncias eram constantes: militares, inspetores (de quarteirão, escolares) e vizinhos fizeram com que recrudescesse o medo. Interferindo diretamente nas escolas, nas famílias e, por conseguinte, nas comunidades, a vida cotidiana foi alterada; homens e mulheres passaram a viver sob rigorosa censura e de certa forma 'emudeceram'. (FÁVERI, 2002, p. 89)

Este silenciamento refletiu também no fechamento de jornais produzidos em línguas estrangeiras, assim como na produção de quaisquer manifestações artísticas e culturais.

Repressões do ponto de vista onomástico aconteceram em vários âmbitos. Clubes de futebol como o Cruzeiro (Minas Gerais) e o Palmeiras (São Paulo), ambos denominados, até 1942, Palestra Itália, tiveram seus nomes substituídos. O primeiro, passou a chamarse Cruzeiro em referência à constelação Cruzeiro do Sul, presente na bandeira brasileira. Já o segundo, recebeu o nome de Palmeiras, que podemos relacionar com a exaltação das palmeiras brasileiras presentes no poema Canção do Exílio de Gonçalves Dias. Não era a motivação verdadeira, mas ambas as trocas reforçavam o ideal nacionalista. Outros clubes que também tinham como componente dos seus nomes a palavra palestra - em italiano designador de clube - passaram por alguma mudança de denominação.

Segundo Gertz (2005, p. 51 e 52), a campanha onomástica expandiu-se também para a toponímia, trocando "nomes de acidentes geográficos, de localidades, de praças e de ruas que tivessem nomes alemão, italiano e japonês [...]".

Como consequência da nacionalização, escolas e sociedades étnicas foram fechadas, pois, citando ainda Gertz (2005, p. 44), a nacionalização eram "as tentativas 
governamentais de eliminar aquilo que era chamado de 'quistos étnicos'. Estes eram constituídos pelas comunidades formadas a partir daqueles grupos imigrantistas que preservam em certa escala o cultivo consciente ou não de características étnico-culturais".

Percebemos um apagamento da identidade linguística italiana que ora era expressada com a língua italiana (para os que a sabiam) ora com diferentes dialetos (esses eram como a língua materna dos que o falavam). O cenário político veta tudo isso e os cidadãos italianos e seus descendentes, em sua grande maioria, aceitam essa repressão para poderem se sentir integrados na nova realidade, na nova pátria. Em muitos casos há a negação da identidade italiana como forma de aceitação, integração e pertencimento. A propósito de pertencimento, Maschio (2005) aponta que no final do século XIX já havia uma preocupação e vontade de aprender o idioma nacional, pois uma vez estabelecidos nas colônias os imigrantes queriam se adaptar ao novo contexto. No caso do Paraná, requerimentos foram enviados com frequência ao Presidente da Província, solicitando escolas para o aprendizado do português. Este interesse se dava no intuito de facilitar "o relacionamento com a população brasileira no momento de negociar seus produtos" (MASCHIO, 2005, p. 30).

O fator medo também foi um contribuinte para a negação da identidade linguística do imigrante e de seus descendentes como afirma Luzzatto (1993) a seguir:

Quando o Brasil declarou guerra ao Eixo (Alemanha + Itália + Japão), aqueles que falavam o talian - e o mesmo acontece com aqueles que falavam alemão - não só eram considerados estrangeiros como também foram convertidos em quinta-colunas, isto é, traidores. Por onde quer que se andasse havia sempre um espião que cuidava se, entre uma conversa e outra, escorregava alguma palavra em talian. (LUZZATTO, 1993, p. 31)

O esmaecimento da língua e da cultura dos descendentes de italianos perdurou até as comemorações do centenário da imigração desta etnia, na década de 1970 (FALCÃO, 2005) quando percebe-se uma afirmação positiva da italianidade, reforçada com o fim da ditadura no Brasil, em 1985 e, posteriormente, com a ascensão econômica da Itália nos anos 90 .

\section{Do Inventário Nacional da Diversidade Linguística à Referência Cultural Brasileira}

Saímos de um contexto de repressão e negação da identidade linguística durante o Estado Novo e, no fim da primeira década dos anos 2000, assistimos a iniciativas em 
prol do Talian como por exemplo, a criação da ASSODITA (Associação dos Difusores do Talian), fundada em novembro de 2008, durante o XII Encontro dos Difusores do Talian, tendo uma representativa participação de radialistas.

Em 10 de junho de 2009, com a Lei n. 13.178, o governo do Rio Grande do Sul, declara o Talian integrante do Patrimônio Histórico e Cultural do Estado. Seguindo a mesma linha, no mesmo estado, o município de Serafina Corrêa, em 13 de novembro do mesmo ano, reconhece o Talian como língua cooficial com a Lei n. 2.615. Na sequência, outros municípios do Rio Grande do Sul como Flores da Cunha e Nova Roma do Sul, em 2015; Antônio Prado, Bento Gonçalves, Fagundes Varela, Guabiju, Nova Pádua e Paraí, em 2016; Camargo e Caxias do Sul, em 2017; e Ivorá, em 2018; também seguiram para a cooficialização dessa língua. No estado de Santa Catarina, Erechim cooficializou o Talian, em $2015^{2}$.

O IPHAN, em 9 de setembro de 2014, inclui o Talian no Inventário Nacional da Diversidade Linguística e o declara Referência Cultural Brasileira, conforme Decreto $n$. 7.387 de 9 de dezembro de 2010. Dessa forma, o Talian começa a ocupar um lugar nunca tido em toda a sua existência.

Ironicamente, esse mesmo órgão que foi criado, durante o governo de Vargas, para zelar pelo patrimônio histórico brasileiro é, hoje, o órgão que reconhece como patrimônio imaterial, a língua negada durante o Estado Novo.

\section{A (des)construção da identidade linguística}

Os imigrantes italianos de Curitiba e região metropolitana são, em sua maioria, provenientes do nordeste da Itália, da região do Vêneto e das províncias de Vicenza e Treviso. Mas encontramos também outros, em menor número, como os beluneses, veroneses, friulanos, mantuanos, bergamascos e trentinos.

Quando esses imigrantes chegaram ao Brasil, o que lhes fazia italianos era o contraste com as outras nacionalidades, com os poloneses, os ucranianos e os alemães como afirma Hall (2000, p. 110) "as identidades são construídas por meio da diferença e não fora dela [...], por meio da relação com o outro, com a relação com aquilo que não é".

A população italiana e seus descendentes apresentam uma característica peculiar

\footnotetext{
2 Dados disponíveis no site do IPOL - Instituto de Investigação e Desenvolvimento em Política Linguística. Línguas cooficiais em municípios brasileiros. Disponível em: $<$ http://ipol.org.br/lista-de-linguas-cooficiais-em-municipios-brasileiros/> Acesso em 20 de junho de 2020.
} 
pois, antes de se dizer italiano eles usam o adjetivo pátrio da região de proveniência para se identificar e isso é percebido de norte a sul. Antes de ser italiano um siciliano é siciliano como um napolitano é napolitano e um veneziano é veneziano. Essa identificação pode ser explicada pelo tardio processo de estado unitário italiano. Em um país com tantas identidades é comum reconhecer essa multiplicidade identitária também na língua já que a Itália sempre foi um tapete de dialetos.

Como já citado, a maior parte dos imigrantes da capital paranaense e região metropolitana possui uma origem comum, o nordeste da Itália. Balhana (1978) afirma que

Para o Brasil vieram predominantemente imigrantes do Vêneto, cuja proporção atingiu $47,68 \%$ do conjunto da imigração italiana (...). Esta proporção tende a elevar-se quando se trata dos contingentes de italianos estabelecidos em núcleos coloniais do Sul do Brasil, nos quais, a proporção de imigrantes oriundos do Vêneto chega a ultrapassar $90 \%$, como ocorre nas colônias italianas do Paraná. (BALHANA, 1978, p. 16)

Dessa forma, os dialetos trazidos por esses imigrantes também têm uma base comum. Com o tempo, misturaram-se entre si, tiveram influência do italiano standard ${ }^{3}$, do português brasileiro e de outras línguas aqui faladas, dando origem a uma koiné identificada como Vêneto Brasileiro e que nós, por questões de política linguística, preferimos chamar de Talian.

A construção da identidade linguística é como aquela da etnicidade, "não se manifesta nas condições de isolamento, é, ao contrário, a intensificação das interações características do mundo moderno e do universo urbano que torna salientes as identidades étnicas" (POUTIGNAT E STREIFF-FENART, 2011, p. 124). A identidade e a etnicidade foram construídas até o momento da Campanha de Nacionalização quando é imposta a desconstrução do que tinha sido edificado e a construção de uma nova identidade, uma etnicidade através da língua portuguesa do Brasil.

Antes da Campanha, a identidade era construída pelo contraste com o outro, podendo ele ser alemão, polonês ou mesmo brasileiro, por exemplo. Após a Nacionalização, todos eram brasileiros, ou pelo menos deveriam se sentir ou ser brasileiros, sem diversidade étnica, sem diferenciações que pudessem ser identificadas pela origem. A Campanha de Nacionalização impôs uma unanimidade étnica.

\footnotetext{
${ }^{3}$ A interferência do italiano standard no Talian foi constatada pelos pesquisadores do CEVEP ao analisar o corpus de entrevistas realizadas no Paraná. Alguns dos falantes de Talian estudaram formalmente a língua italiana.
} 


\section{TALIAN: LÍNGUA VIVA}

\section{A constituição do CEVEP e o acervo das entrevistas}

O CEVEP (Centro de Estudos Vênetos no Paraná) é um grupo de pesquisa cadastrado no CNPq, desde 2018, e tem por objetivo descrever e analisar o Talian, pelo viés da Sociolinguística e o considera língua de herança, conforme o conceito de Ortale (2016):

Língua de herança é a língua com a qual uma pessoa possui identificação cultural e sentimento de pertencimento a determinada comunidade que a usa, seja por laços ancestrais, seja por convivência no mesmo ambiente sociocultural com falantes dessa língua. (ORTALE, 2016, p. 27)

Integram esta iniciativa pesquisadores e alunos das áreas de Linguística, Arquitetura, Educação, Comunicação, História, Design e Direito, além de membros da comunidade italiana de Curitiba e Região Metropolitana, o Museu Municipal Cristóforo Colombo e as Associações Italiana Padre Alberto Casavecchia e Veneti nel Mondo de Colombo.

O grupo se reúne mensalmente para discussão de assuntos relacionados ao Talian e realiza entrevistas sociolinguísticas com os detentores desta língua em Campo Largo, Colombo e Curitiba, as quais já somam um corpus de mais de 70 registros. Este material serve de base para os estudos e a produção de material didático para o ensino de Talian e alimenta todas as frentes de trabalho do Grupo.

A divulgação das ações do grupo acontece em eventos científicos internacionais e nacionais e diretamente nas comunidades detentoras do Talian.

\section{Análise das entrevistas}

Como já explicitado, as entrevistas realizadas com os detentores do Talian são o principal produto do CEVEP. Os entrevistados são descendentes de segunda e terceira gerações, em sua maioria vênetos e moradores de Curitiba e Região Metropolitana. Falam ou entendem (ou ambas as coisas) o Talian e sempre assinam um termo de consentimento de uso das suas respostas para fins de pesquisa. As entrevistas são de cunho sociolinguístico, estruturadas em 46 questões norteadoras da conversa que dura de uma a duas horas e meia, dependendo do entusiasmo do entrevistado para falar sobre o que 
lhe é proposto como insumo. Como nosso trabalho visa analisar e entender a percepção de pertencimento dos entrevistados à cultura italiana (e a língua que a representa) e de como o Talian tenha contribuído - ou não - para esse processo, selecionamos 3 perguntas (insumos) apresentadas aos nossos entrevistados para expor aqui os resultados. São elas:

a) n. 27 Que língua falam/falavam seus avós, pais, irmãos, filhos, amigos, marido...? (Che éngoa palava i tu nuni, to mare, to pare, fradei, soree, fémena, omo, fuiu, amighi?)

b) n. 28 Em algum momento foi proibido falar Talian? O que você sabe? Como era? (Setu se ga bio un tempo che non se podea palar Talian? E come ze stà?)

c) n. 31 Você já sentiu vergonha de falar Talian, por quê? (Gheto bio vergogna de palar Talian? Par cossa?)

Apresentamos aqui as respostas que selecionamos, por amostragem, do nosso corpus de entrevistas.

Para manter a identidade de nossos informantes identificamos apenas o número da entrevista e a data da realização da mesma. Quando ilustramos um diálogo indicamos E para o entrevistador e I para o informante.

A transcrição das entrevistas é de forma livre e para aquelas em que o informante se expressa em Talian colocamos a tradução em nota de rodapé.

Apresentamos, a seguir, a análise das respostas a cada pergunta em forma de blocos. Temos como base o conceito de Balthazar (2016, p. 30) que define atitudes linguísticas como "avaliações, sentimentos ou comportamentos positivos, negativos ou neutros, perante a língua e/ou aos seus usuários na sociedade”. Analisamos então as representações dos falantes sobre a língua começando com a resposta de dois informantes ao insumo 27:

\section{Com quem falava Talian?}

1) Entrevista CO-01 - 30/03/2019

E: Questa éngoa, te palavi soeo co a famegia, co i amighi?

I: Soeo co a famegia, parché gera massa vergogna, ve'. Vergogna parché te navi fora palar de questa magnera eà che i gera ... parché ghe gera... che gnan te go dito, ghe gera i poeachi, che gera puchi, ve', e ghe gera bresiliani e ora iuri i catava un mes-cero massa stragno.

E: Ma iuri non palava e sue éngoe?

I: No, no, no, no, no... i saea, ma i catava i... se... i se... i... se ria de noantri palava taliano e assava noantri con vergogna. Iuri i no saea gnanca palar a sua, che gera soeo el "português", ve'? Ma quando noantri palavino qualchecossa em taliano... Madona mia, quanta... i se ria...

E: I te cogionava? 
I: Cogionava. ${ }^{4}$

2) Entrevista CO-02 - 30/03/2019

$\mathbf{E}$ : Che éngoe che se palava co i nuni, col to pare, co a to mare, co to fradei?

I: Sempre Talian, a casa sempre Talian.

E: Ma co i amighi? Quando te navi catar un amigo? Quando te geri...?

I: Ah... in portughese parché givimo vergogna, ve'. ${ }^{5}$

Percebemos que nesses dois excertos o Talian era língua exclusiva de comunicação com a família. Para falar com os amigos, vizinhos e outras pessoas a língua utilizada era o português denominado por muitos "brasilian". A não utilização do Talian ora se dava por proibição/medo (como veremos no próximo excerto de entrevista) ou por vergonha, como vimos aqui quando se relata que o interlocutor zombava da língua usada. No terceiro bloco apontaremos mais 5 ocorrências com essa temática.

Vamos agora para o excerto do insumo 28:

\section{Proibição do falar Talian}

Em algum momento foi proibido falar Talian? O que você sabe? Como era?

(Setu se ga bio un tempo che no se podea palar Talian? E come ze stà?)

1) Entrevista CO-04 - 13/04/2019

I: Ghe gera a quinta coluna che non podea palare nantra éngoa... eh... ghe gera a fiscalizasson (...) Conforme el posto non podea palar nantra língua. ${ }^{6}$

\footnotetext{
${ }^{4} \mathbf{E}$ : Esta língua, você a falava só com a família, com os amigos?
}

I: Só com a família, porque havia muita vergonha, certo. Vergonha porque você ia pra fora falar desta forma lá que tinha... porque tinha... como te disse, tinha os polacos, que eram poucos, certo, e tinha os brasileiros e então eles achavam uma coisa muito estranha.

E: Mas eles não falavam as suas línguas?

I: Não, não, não, não, não... eles sabiam, mas eles achavam... eles riam se nós falávamos italiano e deixavam-nos com vergonha. Eles não sabiam nem falar a deles, que era só o português, certo? Mas quando nós falávamos qualquer coisa em italiano... Nossa Senhora... quanto que eles riam... E: Eles zombavam de você?

I: Zombavam.

${ }^{5} \mathbf{E}$ : Que língua que se falava com os nonos, com o teu pai, com a tua mãe, com os teus irmãos?

I: Sempre em Talian, em casa sempre Talian.

E: Mas com os amigos? Quando você ia encontrar um amigo? Quando você era...?

I: Ah... em português, porque tínhamos vergonha, certo.

${ }^{6}$ I: tinha a quinta coluna que não podia falar outra língua... é... e tinha a fiscalização (...) conforme o lugar não se podia falar outra língua. 
Verificamos a expressão de medo do entrevistado quando cita a existência da "quinta coluna" neste excerto e no decorrer da entrevista. Alguns registros relatam que a expressão "quinta coluna” surgiu durante a Guerra Civil Espanhola (1936-39) sendo utilizada para indicar os apoiadores de Franco que eram contra o governo de Azaña, da Frente Popular Republicana. As 'quatro colunas' significavam uma disposição militar de ataque, quatro frentes que estavam para chegar em Madri pelos 4 pontos. A quinta, seria então, os outros franquistas infiltrados no meio da população como espiões. A expressão teve sua carga semântica ampliada, mas sempre utilizada em questões bélicas. Aqui no Brasil, a expressão era (em alguns lugares ainda é) empregada para designar um espião que atuava a favor do governo ou um traidor presente em um grupo de amigos.

Analisamos a seguir a transcrição das respostas de 5 informantes sobre a questão da língua relacionada à vergonha:

\section{Vergonha de falar Talian}

Você já sentiu vergonha de falar Talian, por quê? (Gheto bio vergogna de palar Talian? Par cossa?)

\section{1) Entrevista SF-16 - 09/03/2019}

I: A vergogna ga scominsià quando picoli navimo nte scola. I primi dì me ricordo che me mare... nasea mi e un derman, e i primi dì me mare me mandava scola col capelo de pàia. Elora quando rivàvimo là ntea scola, tuti i altri vardava: ma cossa, ma parché questo? Sì bauchi, coloni. E nantri disìno che iera par el sole. E i disea che chea roba lì no'l serve per gnente, ze bruto. Elora ga scomissià live che nantri vedevino che...Nantri pìcoli no capìvino tanti. Nantri volévino essere compagni de chelaltri. Elora ritornàvino casa e disìvino: no vui nar pì co questo capelo. Era una briga sempre.?

\section{2) Entrevista SF-29-05/04/2019}

I: No [ghea vergogna, ma] ghea vergogna da me mare parché iera tosatelo mi, né. Sapia Dio, ghea dódese, trédese ani. Elora no volea che a parlasse in Talian parché i amighi de me pare i iera tuti del sentro. I

\footnotetext{
${ }^{7}$ I: A vergonha começou quando pequenos nós íamos para a escola. Os primeiros dias me lembro que a minha mãe... íamos eu e um primo, e os primeiros dias minha mãe me mandava para a escola com o chapéu de palha. Então quando chegávamos na escola, todos os outros olhavam: mas o que, mas por que isso? Vocês são bobos, colonos. E nós dizíamos que era por causa do sol. E eles diziam que aquela coisa ali não servia para nada, era feia. Então começou ali que nós víamos que... nós pequenos não entendíamos muitas coisas. Nós queríamos ser iguais àqueles outros. Então voltávamos para casa e dizíamos: não quero mais ir com este chapéu. Era uma briga sempre.
} 
iera Ney Braga, Fabiano Braga Corte. Tuti gente politichi che i vegnea su. $^{8}$

3) Entrevista SF-14 - 09/03/2019

I: Quando go scomissià a imparar l'italiano proprio i maestri i disea: "no no no quello è dialetto! No ze questa parola." Lora per me el Talian è come se fosse in portoghese el caipira. Elora sentia vergogna. ${ }^{9}$

No primeiro excerto a necessidade de pertencimento a um grupo é evidente com a frase "Nantri volevino essere compagni de chelaltri - Nós queríamos ser companheiros/ iguais a eles". E para ser iguais aos colegas era necessário negar, por vergonha, o Talian. A vergonha é presente não somente na língua, mas também no modo de se vestir (o chapéu de palha) que remetia ao colono, àquele que não sabe falar o português ao "baúco". Faggion (2007, p. 13) relata a mesma ocorrência em suas pesquisas e podemos associar à sua fala não somente o exemplo 1 , mas também o 3 :

Era na escola que o falante ítalo-brasileiro encontrava o outro que o fazia ver-se diferente: os colegas que riam de sua maneira de falar, ou o próprio professor, cuja linguagem padrão parecia estabelecer um limite ou uma barreira (FAGGION, 2007, p.13).

No segundo excerto, apresenta-se a negação do falante e a vontade que de que houvesse o apagamento linguístico dos pais. Ele não sentia vergonha, pois não falava a língua com os colegas, mas os seus pais (no caso a mãe) a falavam e isso o constrangia. A esse propósito, Poutignat e Streiff-Fenart (2011, p. 71), considerando a construção de uma identidade, amparada no étnico e tendo como base as pesquisas de Hansen (1938) e Glazer (1954) afirmam que “grupos étnicos como 'nações fantasmas' e a célebre 'lei de Hansen' (daquilo que o filho quer esquecer, o neto quer se lembrar), estabelecem que uma identidade étnica dos imigrantes tende a ser rejeitada na segunda geração mas revitalizada na terceira".

\footnotetext{
${ }^{8}$ I: Não [tinha vergonha, mas] tinha vergonha da minha mãe porque eu era menininho, né. Sabe Deus, tinha doze, treze anos. Então não queria que ela falasse em Talian porque os amigos do meu pai eram todos do centro. Eles eram Ney Braga, Fabiano Braga Corte. Todos políticos que vinham aqui.

${ }^{9}$ I: Quando comecei a aprender o italiano mesmo os professores diziam: 'não, não, não, aquilo é dialeto! Não é essa palavra.' Então para mim o Talian é como se fosse em português, o caipira. Então sentia vergonha.
} 
4) Entrevista CO-03 - 31/03/2019

E: Questa è una domanda: gheto mai sentisto vergogna de palar Talian? I: Sì, sì, go sentio vergogna, parché quando son nata scoea tuti i palava diferente. E dopo quando se palava qualcosa cussita, è... i dizea che gera tuto erà.

E: Ma i te cogionava?

I: Sì me cogionava, me cogionava. $\mathrm{E}$ ora mi rivava casa, me sarava su so, me sarava su e scuminsiava a dir teerrra... terrra... parché mi no saea dir "terra", dizia tera. Gera tuto con un R soeo e ora i mi cogionava. ${ }^{10}$

5) Entrevista CO-19-27/04/2019

E: Sito nata scoea?

I: Sì

E: E come gereo?

I: Ah... era difícil

E: So el scominsio, sol scominsio...

I: Soe scomesso ${ }^{11}$ era difícil, porque a gente falava diferente, um "erre" só. Então a gente foi numa escola onde tinha muita criança diferente [choro]

E: Isso era aqui na Colônia?

I: Não. Era na Campina Grande do Sul. [chorando] E eles davam muita risada do jeito da gente falar. E naquela sala, por ser num loteamento, lá onde é o Eugênia Maria, só tinha eu de diferente. Então foi difícil. [choro]

$\mathbf{E}:$ E isso dói pra você até hoje?

I: Dói, sim. E daí, é... eles não entendiam e a professora também, ela não entendia. Ela era de... italiana, descendente também, mas ela podia fazer alguma coisa, ela devia né, mas ela não entendia. Então, quando as outras crianças falavam assim... é... ela não falava nada e a gente ficava muito envergonhado. Mas daí passou, foi passando de ano e tal, mas sempre com aquela marca. Depois quando eu fiz nove anos, nós nos mudamos pra cá. Daí aqui na Colônia Faria eram mais crianças igual a mim. A professora já era outra, já sabia lidar com todo tipo de situação,

${ }^{10} \mathbf{E}$ : Esta é uma pergunta: você já sentiu vergonha de falar Talian?

I: Sim, sim, senti vergonha, porque quando fui para a escola todos falavam diferente. E depois quando se falava qualquer coisa assim... é... eles diziam que estava tudo errado.

E: Mas eles zombavam de você?

I: Sim, eles me zombavam, me zombavam. E então eu chegava em casa, me fechava no, me fechava e começava a dizer teerra... terra... porque eu não sabia dizer 'terra', dizia terá. Era tudo com um R só e então eles me zombavam.

${ }^{11} \mathbf{E}$ : Você foi para a escola?

I: $\operatorname{Sim}$.

E: E como era?

I: Ah... era difícil.

E: No começo, no começo...

I: No começo 
as crianças daqui já falavam mais parecido comigo, aí foi indo. (...) Eu nunca falei sobre isso (choro). Depois, foi nessa época que decidi que eu queria ser professora pra trabalhar com esse tipo, com todo mundo que é diferente na sala, por isso.

Os exemplos 4 e 5 são entrevistas cheias de emoção que trazem questões recorrentes em outras entrevistas: a questão do sotaque, da realização do fonema /r/. No português brasileiro temos $\mathrm{o} / \mathrm{r} /$ vibrante ou fricativo e $\mathrm{o} / \mathrm{r} /$ tepe, já na maioria dos dialetos do norte da Itália temos somente a realização de uma vibrante simples o que influencia a realização do /r/ em alguns descendentes aqui no Brasil. No fim da entrevista 4 temos na primeira pronúncia "terra" uma fricativa lábio-velar sonora [v] e não um som de /r/. Quando a informante repete a palavra, faz uma aproximante. Percebemos então o quanto traumatizante foi a questão do sotaque para essa informante que tem o Talian como língua materna e aprendeu o português somente na escola. Na sequência, apresentamos a imagem gerada pelo Software Praat para a pronúncia de 'terra' e 'tera' segundo a entrevistada:

\section{FIGURA 1 - IMAGEM GERARA PELO PRAAT PARA A PRONUNCIA 'TERRA' E 'TERA' SEGUNDO A ENTREVISTADA ${ }^{12}$}

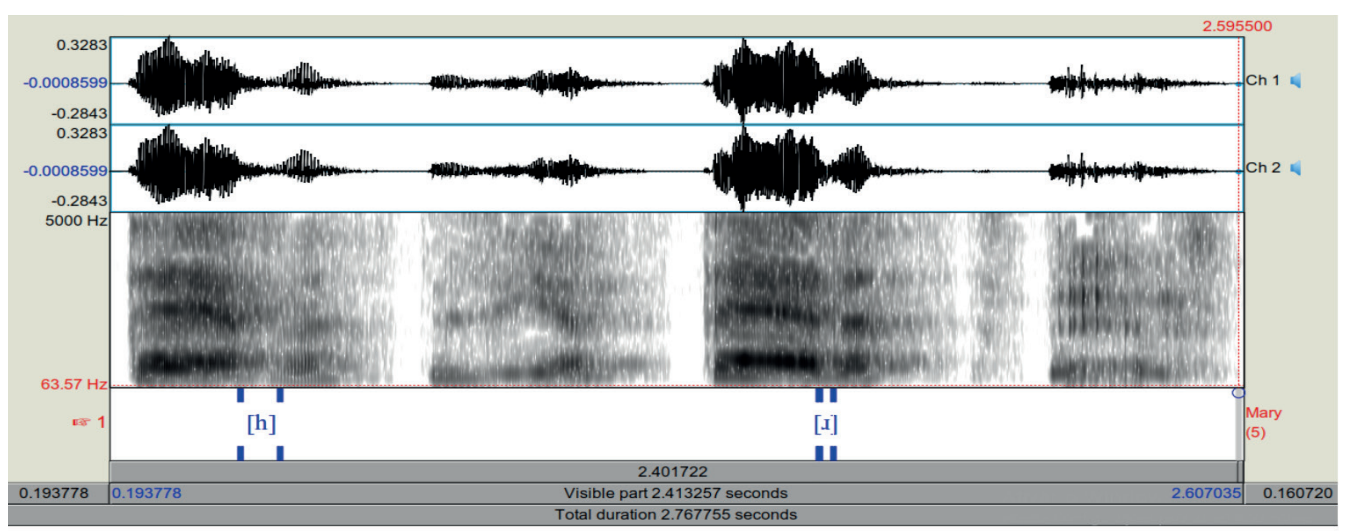

FONTE: SILVA

$\mathrm{Na}$ entrevista 5 percebe-se que a informante começa falando em Talian e logo no início aborda o tema da pronúncia do 'r' o que claramente a perturba muito e a faz mudar a língua usada durante a entrevista, utilizando então, o português até o final. Segundo Nettle e Romaine (2002, p. 18-19 apud FROSI, 2007, p. 149), "molte persone cessano di

\footnotetext{
${ }^{12}$ Análise e captura da imagem no Software Praat são créditos de Adelaide Hercília Pescatori Silva a quem agradecemos.
} 
parlare la loro lingua come forma di autodifesa e come strategia di sopravvivenza ${ }^{13}$ ". O relato da entrevistada é muito comovente, mas o seu sofrimento fez com que, enquanto professora, soubesse valorizar as diferenças sem estigmatizá-las.

\section{CONSIDERAÇÕES FINAIS}

O Talian foi silenciado, mas seu eco permaneceu adormecido em vários detentores que, aos poucos, conseguem lhe restituir a voz. Os imigrantes e seus descendentes introduziram uma materialidade simbólica da língua e, mesmo em muitos casos tendo sofrido apagamento e silenciamento, como constatamos na análise de alguns trechos das entrevistas aqui apresentados, é a existência material e memória discursiva, constituinte inseparável do sujeito que ela constrói.

Durante o Estado Novo, o Talian foi restrito somente ao ambiente familiar, uma consequência direta da Campanha de Nacionalização. Esse apagamento, mesmo que parcial em algumas famílias, deixou cicatrizes profundas revelando medo e vergonha, sentimentos que refletem as atitudes linguísticas observadas nos entrevistados.

O medo e a vergonha foram também, os principais motivos que fizeram com que muitos descendentes negassem a sua língua de herança e/ou diminuíssem a sua difusão às gerações seguintes.

Porém, apesar de constantes relatos de vergonha decorrente sobretudo do sotaque, percebemos atitudes positivas dos falantes, como a presente no excerto que segue e que sintetiza o título deste artigo 'língua negada e (re)conhecida':

\section{Entrevista SF-16 - 09/03/2019}

Quando ieramo giovani, toseti, ghemo na serta vergogna de parlare, de cheo, de queo sotache con quea letra "erre" caregada inte e parole, che tuti ridea. Alora achilo ghemo medo che abandonà de parlare e uncò vedemo che ze un, un sbaglio, no? Ze belo parlare, parché se remete là, a quei ani dei nostri antepassati, nè. E uncó ghemo orgulio de queo che ghivimo vergogna a tanti ani in drio. ${ }^{14}$

13 Muitas pessoas param de falar a sua língua como forma de autodefesa e como estratégia de sobrevivência.

${ }^{14}$ I: Quando éramos jovens, meninos, tínhamos uma certa vergonha de falar, daquele sotaque com aquela letra "erre" carregada nas palavras, que todos riam. Então aquilo meio que deixamos de falar e hoje vejo que não era um erro, não. É bonito falar, porque se remete àqueles anos dos nossos antepassados, né? E hoje temos orgulho daquilo que tínhamos vergonha há tantos anos. 
Entendemos que cabe a estudos futuros analisar os motivos que instigaram essa mudança e que contribuem para manter viva essa referência cultural brasileira. Afinal, como dizia o ilustre pesquisador do Talian, Darcy Loss Luzzatto, "La léngua l'è el sataron dela cultura, una non vive sensa l'altra, se una la more, quelantra non dura!"15

\footnotetext{
${ }^{15}$ A língua é a base da cultura, uma não vive sem a outra, se uma more, aquela outra não dura.
} 


\section{REFERÊNCIAS:}

BALHANA, A. P. Santa Felicidade, uma paróquia veneta no Brasil. Curitiba: Fundação Cultural de Curitiba, 1978.

BALTHAZAR, L. Atitudes linguísticas de ítalobrasileiros em Criciúma (SC) e região. 2016. 298 f. Tese (Doutorado em Letras) - Setor de Ciências Humanas, Universidade Federal do Paraná, Curitiba, 2016.

CAMPOS, C. M. A política da língua na era Vargas. Campinas: Editora Unicamp, 2006.

FALCÃO, L. F. Brasiliani e Italianos: reflexões sobre a instituição de uma identidade italiana no Brasil contemporâneo. In: RADIN, José C. (Org). Cultura e identidade italiana no Brasil: algumas abordagens. Joaçaba: UNOESC, 2005.

FAGGION, C. M. Bilinguismo precoce e estigma. In: GIRON, L. S.; RADÜNZ, R. Imigração e Cultura. Caxias do Sul: Educs, 2007. p. 133-140.

FÁVERI, M. Memórias de uma (outra) guerra. Cotidiano e medo durante a Segunda Guerra em Santa Catarina. 2002. 392 f. Tese (Doutorado em História Cultural) - Centro de Filosofia e Ciências Humanas, Universidade Federal de Santa Catarina, Florianópolis, 2002.

FROSI, V. M. Bilinguismo de português e dialetos italianos: nossa história, nossa língua, nossa origem. In: GIRON, L. S.; RADÜNZ, R. Imigração e Cultura. Caxias do Sul: Educs, 2007. p. 143-152.

GERTZ, R. E. O Brasil verdadeiro contra o Brasil falso. In: DALMOLIN, C. R. Mordaça Verde e Amarela: imigrantes e descendentes no Estado Novo. Santa Maria: Pallotti, 2005. p. 37-58.

HALL, S. Quem precisa de identidade. In: SILVA, T. T. Identidade e diferença: a perspectiva dos estudos culturais. Petrópolis: Vozes, 2000. p. 103-133.

LUZZATTO, D. L. El nostro parlar: e outras crônicas. Porto Alegre: Sagra-DC Luzzatto, 1993.

MASCHIO, E. C. F. A Constituição do processo de escolarização primária no município de Colombo - Paraná (1882-1912). 2005. 175 f. Dissertação (Mestrado em Educação) Setor de Educação, Universidade Federal do Paraná, Curitiba, 2005. 
MASCHIO, E. C. F. A escolarização dos imigrantes e de seus descendentes nas colonias italianas de Curitiba, entre táticas e estratégias (1875-1930). 2012. 341 f. Tese (Doutorado em Educação) - Setor de Educação, Universidade Federal do Paraná, Curitiba, 2012.

ORTALE. F. L. A formação de uma professora de italiano como língua de herança: o pós-método como caminho para uma prática docente de autoria. 2016. 163 f. Tese (Livre Docência em Língua italiana) - Faculdade de Filosofia, Letras e Ciências Humanas, Universidade de São Paulo, São Paulo, 2016.

PAYER, M. O. Memória da língua. Imigração e nacionalidade. São Paulo: Escuta, 2006

POUTIGNAT, P.; STREIFF-FENART, J. Teorias de etnicidade: seguido de grupos étnicos e suas fronteiras de Fredrik Barth. São Paulo: UNESP, 1998.

RENK, V. E., MASCHIO, E. C. F. Por uma história da escola primária no contexto de imigração: experiências de escolarização entre imigrantes eslavos e peninsulares itálicos no Paraná. Rev. Bras. Hist. Educ [online], Maringá, v. 20, e106, 2020.

TRENTO, A. Do outro lado do Atlântico: um século de imigração italiana no Brasil. São Paulo: Nobel, 1988. 